\title{
Burguesia industrial e a construção de uma agenda de desenvolvimento: a perspectiva da FIERGS
}

\author{
Marco André Cadoná \\ Programa de Pós-Graduação em Desenvolvimento Regional / Universidade de Santa Cruz do Sul (UNISC)
}

Recebido: 30/03/2019 Versão revisada (entregue): 06/11/2019 Aprovado: 14/11/2019

\begin{abstract}
Resumo
Com base nos posicionamentos políticos da FIERGS (Federação das Indústrias do Estado do Rio Grande do Sul) no contexto das eleições de 2018, o artigo apresenta a agenda de desenvolvimento defendida pela burguesia industrial do Rio Grande do Sul. Depois de resgatar a participação da FIERGS na discussão sobre o desenvolvimento no Rio Grande do Sul, desde os anos 1980, são analisados os cinco temas que estruturaram a agenda de desenvolvimento, defendida por essa fração subnacional da burguesia industrial no Brasil nas eleições de 2018: 1. Segurança jurídica, desburocratização, simplificação e eficiência administrativa/tributária do setor público; 2. Infraestrutura e logística; 3. Adequação do tamanho e peso do setor público, estabilidade macroeconômica e financiamento; 4. Inserção externa e novas tecnologias; 5. Empreendedorismo, indústria e sociedade. $\mathrm{O}$ artigo indica que a burguesia industrial do Rio Grande do Sul atua como força social e coletivamente organizada na defesa de uma agenda de desenvolvimento sustentada num processo histórico de afirmação/reafirmação dos pressupostos neoliberais.
\end{abstract}

Palavras-chave | Agenda de desenvolvimento; burguesia industrial; eleições estaduais; FIERGS; Rio Grande do Sul.

Código JEL | K16 L26 Z13

Industrial bourgeoisie and the construction of a development agenda: the perspective of FIERGS

\begin{abstract}
Based on the political positions of FIERGS (Rio Grande do Sul State Federation of Industries) in the context of the 2018 elections, the article presents the development agenda defended by the industrial bourgeoisie in Rio Grande do Sul. After rescuing the participation of FIERGS on the discussion about development in Rio Grande do Sul, since the 1980s, the five themes that structured the development agenda defended by this subnational fraction of the industrial bourgeoisie in Brazil in the 2018 elections are analyzed: 1. Legal security, debureaucratization, simplification and administrative / tax efficiency on the public sector; 2. Infrastructure and
\end{abstract}


logistics; 3. Adequacy of the size and weight of the public sector, macroeconomic stability and financing; 4. External insertion and new technologies; 5. Entrepreneurship, industry and society. The article indicates that the industrial bourgeoisie in Rio Grande do Sul acts as a social force and collectively organized in the defense of a development agenda sustained in a historical process of affirmation/reaffirmation on neoliberal assumptions.

Keywords | Development agenda; FIERGS; industrial bourgeoisie; Rio Grande do Sul; state elections.

JEL-Code | K16 L26 Z13

\section{Burguesía industrial y la construcción de una agenda de desarrollo: la perspectiva de la FIERGS}

\section{Resumen}

Con base a los posicionamientos políticos de la FIERGS (Federación de Industrias del Estado de Rio Grande do Sul), en el contexto de las elecciones de 2018, el artículo presenta la agenda de desarrollo defendida por la burguesía industrial de Rio Grande do Sul. Después de rescatar la participación de la FIERGS en la discusión sobre el desarrollo en Rio Grande do Sul, desde los años 1980, son analizados los cinco temas que estructuraron la agenda de desarrollo, defendida por esa fracción sub-nacional de la burguesía industrial en Brasil en las elecciones de 2018: 1. Seguridad jurídica, desburocratización , simplificación y eficiencia administrativa / tributaria del sector público; 2. Infraestructura y logística; 3. Adecuación del tamaño y peso del sector público, estabilidad macroeconómica y financiamiento; 4. Inserción externa y nuevas tecnologías; 5. Emprendedorismo, industria y sociedad. El artículo indica que la burguesía industrial de Rio Grande do Sul actúa como una fuerza social y colectivamente organizada en defensa de una agenda de desarrollo sostenida en un proceso histórico de afirmación/reafirmación de los supuestos neoliberales.

Palabras clave | Agenda de desarrollo; burguesía industrial; elecciones estaduales; FIERGS; Rio Grande do Sul.

Codigo JEL | K16 L26 Z13

\section{Introdução}

Este artigo apresenta uma análise sobre a participação política da burguesia industrial na discussão de uma agenda de desenvolvimento no Rio Grande do Sul. Ao investigar os posicionamentos políticos da Federação das Indústrias do Estado do Rio Grande do Sul (FIERGS) nas eleições de 2018, procura-se desvendar o projeto político de desenvolvimento defendido pela burguesia industrial no Rio Grande do Sul, num momento em que a crise econômica e política assinalou o 
término de um período de políticas "neodesenvolvimentistas" no Brasil, implementadas pelos governos liderados pelo Partido dos Trabalhadores (PT), e a retomada da orientação neoliberal na condução da políticas governamentais com a eleição de Jair Bolsonaro para presidente da República.

Não se trata apenas de um registro histórico desse processo político e dos posicionamentos da mais importante instituição de representação dos interesses de classe da burguesia industrial no Rio Grande do Sul. Mais do que isso, pretende-se contribuir para a análise de duas questões importantes na bibliografia existente sobre a participação política da burguesia industrial na dinâmica de desenvolvimento do capitalismo no Brasil: sua capacidade de atuação enquanto força social e coletivamente organizada e seu comprometimento na construção de agendas de desenvolvimento.

Nessa direção, inclusive, no artigo posiciona-se em favor da tese de que a burguesia industrial no Rio Grande do Sul demonstra, por meio da atuação de suas instituições de representação de interesses de classe (como é o caso da FIERGS), capacidade política de articulação de propostas de desenvolvimento que, mais do que possibilidades de consenso intraclasse, colocam o segmento industrial gaúcho como um sujeito político importante na discussão de agendas de desenvolvimento para e no Rio Grande do Sul. Agendas essas que, em que pese as adaptações conjunturais e as divergências possíveis entre lideranças e setores econômicos, articulam-se em torno de uma recorrente crítica ao Estado, principalmente no que diz respeito à sua atuação social e de regulação das relações entre capital e trabalho, mas, ao mesmo tempo, de defesa da presença do Estado na criação de condições favoráveis aos investimentos do capital.

\section{Burguesia industrial, atuação política e construção de agendas de desenvolvimento}

A análise da participação da FIERGS na discussão de agendas de desenvolvimento permite o enfrentamento de suas problemáticas importantes na bibliografia que investiga a formação de classe da burguesia industrial no Brasil: sua capacidade de atuação como força social e coletivamente organizada visando a defesa de seus interesses de classe, bem como sua participação na discussão acerca das dinâmicas de desenvolvimento do capitalismo nas unidades subnacionais do País.

No que diz respeito à sua capacidade política de defesa de seus interesses de classe, na bibliografia que analisa a atuação política dessa fração da burguesia no Brasil esse é um dos principais pontos de discordância. Para alguns pesquisadores, já a partir do período de "abertura democrática" (1980) a burguesia industrial demonstrou grande capacidade em atuar como força social e coletivamente organizada, liderada por entidades de representação que demonstram habilidade 
política para viabilizar uma ação conjunta em torno de objetivos comuns (DREIFUSS, 1986; BARBOSA, 2003; MANCUSO; OLIVEIRA, 2006). Para outros pesquisadores, no entanto, a atuação política da burguesia industrial a partir daquele período tem se caracterizado pela "fragmentação excessiva", o que, agravado pela inexistência de associações empresariais de maior abrangência e capazes de organizar a ação coletiva, inviabiliza uma ação conjunta em torno de objetivos comuns (DINIZ; BOSCHI, 2004; DINIZ; PEREIRA, 2008).

Importante destacar que essa segunda tese marcou os estudos sobre a atuação da burguesia industrial no processo de "abertura política" e de democratização do país iniciado durante a década de 1980. Em especial a partir dos estudos de Eli Diniz, a tese segundo a qual a "burguesia nacional" era passiva e se acomodava diante do poder do estado e do capital estrangeiro ${ }^{1}$ foi amplamente criticada. Embora não tenha discordado quanto à falta de hegemonia política da burguesia industrial no processo histórico de desenvolvimento capitalista no país, Diniz não aceitou que disso decorresse uma suposta "fragilidade política". Demonstrou, assim, a influência e o poder político que, especialmente, as "elites industriais" alcançaram junto aos centros de decisão estatal e argumentou ser possível perceber que os industriais constituíram, ao longo do processo de desenvolvimento do capitalismo no país, um modo de relacionamento com o Estado que permitiu uma intervenção ativa em questões que estavam diretamente vinculadas aos seus interesses de classe (DINIZ: BOSCHI, 1978).

Coerente a essa perspectiva de análise, os estudos de Eli Diniz, a partir dos anos 1980, destacam a capacidade de intervenção política das elites industriais nas instâncias de decisão estatal. No entanto, enfatizam também o caráter restrito dessa participação, tendo em vista a heterogeneidade de interesses, o caráter corporativo de seu comportamento político e a falta de uma "entidade de cúpula capaz de representar a totalidade da categoria empresarial na definição de estratégias globais de ação política" (DINIZ: BOSCHI, 2004, p. 54). Assim, para o período posterior à "abertura democrática" se destacaria no comportamento político da burguesia industrial:

[...] sua fraqueza enquanto ator coletivo, a despeito da força relativa de alguns de seus setores, da importância de seus recursos organizacionais, do porte econômico de muitas empresas e do peso das conexões pessoais de segmentos destas elites com as autoridades estatais. A baixa

\footnotetext{
1 Tese defendida por importantes cientistas sociais no Brasil vinculados à teoria da dependência, tais como Fernando Henrique Cardoso e Luciano Martins. Esses teóricos, já a partir da década de 1960, criticaram a tese nacional-desenvolvimentista, segundo a qual haveria uma "burguesia nacional" capaz de liderar um projeto de desenvolvimento capitalista de forma nacional e autônoma e defenderam que, no caso brasileiro, os "setores nacionais do empresariado" se apoiavam num sistema de alianças (com a burocracia estatal e com o capital estrangeiro) no qual a eles estava reservado não mais do que uma posição de "caudatária dos grandes grupos monopólicos, ou como dependente do setor público” (CARDOSO, 1964, p. 107).
} 
capacidade de ação conjunta, por sua vez, pode ser explicada em função de uma série de fatores [...] tais como, as características organizacionais da estrutura corporativa de representação de interesses instaurada nos anos 1930, especialmente a falta de uma organização de cúpula de caráter multissetorial, capaz de agir e de falar em nome do conjunto da classe empresarial, a incapacidade histórica do empresariado no sentido de formular plataformas de teor abrangente incorporando demandas de outros setores, sobretudo da classe trabalhadora, a baixa tradição de acordos interclasse e, finalmente, o papel do Estado como formulador/executor das políticas econômicas do país [...] (DINIZ; PEREIRA, 2008, p. 15).

Entende-se que a ênfase no "caráter corporativo", na "heterogeneidade de interesses" e, mais do que isso, no reduzido grau de articulação classista da burguesia industrial no Brasil relativiza a capacidade demonstrada por essa fração burguesa no país já a partir da década de 1980. Bem como obscurece o significado histórico de sua participação política na defesa de reformas (neoliberais) no Estado e na economia do país desde aquela década.

A heterogeneidade de interesses é constituinte de sua experiência de formação de classe, pois não há uma "burguesia monolítica" (BARBOSA, 2003). Sua constatação, porém, não relativiza a capacidade política demonstrada por essa fração burguesa de atuar como força social e coletivamente organizada em defesa de seus interesses de classe, posicionando-se ativamente em favor de determinadas direções e projetos históricos de desenvolvimento do capitalismo no país, e contra direções e projetos defendidos por forças sociais e políticas identificadas como antagônicas aos seus interesses de classe.

Exemplos dessa capacidade política demonstrada pela burguesia industrial podem ser encontrados tanto no processo de articulação intraclasse quanto nas formas de atuação política junto às instâncias de poder governamental (Legislativo e Executivo, nas esferas estaduais e nacional). Os Encontros Nacionais da Indústria (Enais), por exemplo, promovidos anualmente, desde 2006, pela Confederação Nacional da Indústria (CNI), são ilustrativos. Desde que foi criado, todo o ano as federações estaduais da indústria de todo o país articulam uma agenda de discussão em seus estados, da qual resulta a formação de comitivas que participam dos Enais, onde as lideranças industriais do país definem uma agenda que orienta suas ações políticas tanto com o Executivo quanto com o Legislativo. Nesses encontros, além de uma "Carta da Indústria", são elaboradas "Agendas Legislativas da Indústria" que, uma vez aprovadas, tornam-se referências nas articulações políticas tanto das lideranças quanto das entidades de representação da indústria no Congresso Nacional, mas, também, nas pressões que exercem diretamente junto aos deputados federais e senadores (CADONÁ, 2009). 
Essa capacidade de articulação classista, aliás, ficou evidenciada a partir da década de 1980. E os exemplos ilustrativos são vários: o apoio consensual ao processo de "abertura democrática", controlado de cima e sem grandes rupturas (DREIFUSS, 1986); o suporte (ainda que com críticas pontuais, enfatizas principalmente nos momentos de agravamento da crises econômicas) às reformas neoliberais defendidas ao longo dos anos 1990 (CADONÁ, 2009; MANCUSO; OLIVEIRA, 2006); o apoio crítico aos governos do Partido dos Trabalhadores, a partir de 2003, com ênfase na defesa de reformas neoliberais e críticas às direções (e profundidade) das políticas de distribuição de renda (BOITO JR., 2018); e, num período mais recente, a articulação política em defesa às reformas propostas pelo governo de Michel Temer (2016 - 2018) e ao seu projeto "Uma ponte para o Futuro" (BOITO JR., 2018).

Claro que essa articulação classista ocorre em contextos históricos marcados por conflitos e contradições que decorrem não somente do processo de democratização no país, mas, também, da dinâmica de desenvolvimento e de inserção do "capitalismo brasileiro" no processo de mundialização do capital. Nesse sentido, faz-se importante adotar uma perspectiva de análise atenta à complexidade das relações entre as formas coletivas de atuação classista das classes sociais com as circunstâncias históricas concretas. Essa questão torna-se importante, inclusive, para a compreensão de divergências existentes entre setores econômicos e, mesmo, entre segmentos regionais em torno de direções políticas e ideológicas assumidas pelas lideranças industriais em diferentes conjunturas.

Por exemplo, a FIERGS nunca se posicionou contrária à abertura da economia e à integração econômica proposta a partir da constituição do Mercado Comum do Sul (Mercosul). No entanto, desde a década de 1980 mantém-se articulada na defesa de restrições e políticas compensatórias para os setores da indústria gaúcha (de alimentação, por exemplo) que enfrentam maior concorrência com os produtos de outros países-membros do Mercosul, em especial a Argentina (CADONÁ, 2009).

Adotar uma perspectiva de análise dessa natureza torna-se importante, nesse sentido, para uma compreensão mais clara da defesa da burguesia industrial aos projetos de reformas neoliberais no país. Ainda que o posicionamento favorável ao neoliberalismo mistifique práticas de defesa de interesses corporativos e setoriais, é preciso compreender o significado histórico que o ideário neoliberal assumiu no comportamento político e ideológico da burguesia industrial no Brasil. Desde os anos 1980, a aproximação com o ideário neoliberal tem se colocado como uma estratégia política e ideológica de defesa de reformas no Estado e na economia, mas, principalmente, contrária a políticas que objetivam avançar na garantia de direitos sociais e trabalhistas.

Nesse sentido, se a análise da adesão da burguesia industrial ao neoliberalismo precisa estar atenta às incongruências e, inclusive, contradições entre um discurso 
que ressalta as virtudes do mercado e uma prática política que se acoberta sob o manto protetor da intervenção estatal, não pode se descuidar, igualmente, da importância que essa concepção política e ideológica assume em sua atuação política em favor da dissociação entre desenvolvimento capitalista e democracia.

Atenta a essa perspectiva, na análise apresentada neste texto não se toma a articulação classista da burguesia industrial como um dado. Antes pelo contrário, sua capacidade de atuação social e coletivamente organizada precisa ser tomada como um problema, um processo a ser investigado. Mas, ao mesmo tempo, destaca-se a capacidade que algumas "instituições tradicionais" de representação dos interesses demonstram ter ao se colocarem como "elite orgânica" da burguesia industrial, constituindo-se como agentes coletivos com capacidade de "visualizar objetivos globais" (e capazes de aglutinar os interesses dos diferentes setores e segmentos que compõem a estrutura industrial no país) e de "operacionalizar a condução das ações requeridas em todos os campos para alcançar suas metas" (DREIFUSS, 1986, p. 23).

Em relação à segunda questão (participação na discussão de agendas de desenvolvimento), é importante destacar que, no caso da burguesia industrial no Rio Grande do Sul, pelo menos desde a década de 1990 ficou cada vez mais claro para suas lideranças que, diante da mundialização do capital e da reorientação neoliberal do Estado brasileiro, havia a necessidade de uma intervenção política mais incisiva, principalmente na definição de agendas subnacionais de desenvolvimento. Seja visando criar condições políticas mais favoráveis aos investimentos de capital já localizados no território estadual, seja para atrair novos investimentos produtivos (principalmente do grande capital mundializado), diversificando a estrutura industrial e fomentando uma nova dinâmica de desenvolvimento econômico no território gaúcho (CADONÁ, 2009).

A preocupação com a questão subnacional, aliás, não era novidade nos posicionamentos políticos da burguesia industrial durante a década de 1990. Pelo menos desde a década de 1950, numa perspectiva de "descentralização" da dinâmica de desenvolvimento do capitalismo no país, diferentes "burguesias estaduais" instrumentalizaram seus governos subnacionais visando criar condições mais favoráveis de "integração competitiva" de seus respectivos territórios naquela dinâmica de desenvolvimento. No Rio Grande do Sul, durante a década de 1970, a instalação do Polo Petroquímico de Triunfo se colocou naquele contexto de pressão da burguesia gaúcha para que o Rio Grande do Sul tivesse uma maior participação nos investimentos do capital realizados durante os governos militares (1964 -1985) (GROS, 1987).

Durante a década de 1980, a preocupação com o desenvolvimento estadual também esteve presente nas mobilizações da burguesia industrial no Rio Grande do Sul. No final daquela década, inclusive, aquela preocupação levou a FIERGS à elaboração de um documento (que ficou conhecido como "Relatório Sayad"), por 
meio do qual fez um diagnóstico do setor público estadual, recomendando sua reestruturação. O referido documento propunha, por exemplo, como forma de aumentar a capacidade de investimento dos governos gaúchos e de apoiar a inciativa privada localizada em território estadual: a transferência da Companhia Riograndense de Telecomunicações (CRT) para o sistema Telecomunicações Brasileiras S/A (TELEBRÁS); a redução na folha de pagamento do funcionalismo público; e uma reforma administrativa capaz de reduzir os gastos públicos (GROS, 1990; CADONÁ, 2009).

Já naquelas décadas, um pressuposto importante na interpretação da burguesia industrial acerca do desenvolvimento do capitalismo no Rio Grande do Sul estava presente em sua participação na discussão de uma agenda de desenvolvimento subnacional. Havia o pressuposto de que duas das principais especificidades do desenvolvimento do capitalismo no território gaúcho, em especial a partir da segunda metade do Século XX, estavam vinculadas, por um lado, à estrutura econômica fortemente caracterizada por pequenas e médias indústrias e, por outro, pela dificuldade de atrair capital estrangeiro. Isto em decorrência não somente de estrutura econômica pouco competitiva, mas, também, de uma tradição política marcada pela presença de forças políticas (como foi o caso do Partido Trabalhista Brasileiro na década de 1960) resistentes à participação do capital estrangeiro na dinâmica de desenvolvimento no Rio Grande do Sul (LAPIS, 1989).

Durante a década de 1990, a preocupação com a questão subnacional tornou-se ainda mais importante. Em primeiro lugar, tornou-se uma preocupação situada num novo contexto de desenvolvimento do capitalismo em nível nacional. A partir de então, a abertura da economia, a reestruturação neoliberal do Estado, a política de atração de capital internacional, o maior descomprometimento dos governos nacionais com o desenvolvimento regional e a vinculada guerra fiscal promovida por diferentes governos estaduais ressaltou a importância de uma intervenção mais ativa na esfera subnacional. Mas, além disso, o contexto político sul-rio-grandense, principalmente a partir de 1994, passou a ter um componente novo. Pela primeira vez, forças sociais e políticas vinculadas às classes trabalhadoras no estado, que desde o processo de "abertura democrática" vinham confrontando-se diretamente com os interesses da burguesia no país, conquistaram um espaço político com grande possibilidade de colocá-las à frente do executivo estadual.

Naquele contexto de polarização política e ideológica, a FIERGS passou a ter maior participação política na construção de propostas de desenvolvimento para o Rio Grande do Sul. Nessa direção, desde o início da década de 1990, a FIERGS discutiu agendas de desenvolvimento, em especial nos períodos eleitorais. Tais agendas, transformadas em documentos da instituição, desde então foram discutidas, em todo o território gaúcho, tanto com lideranças locais e regionais quanto com os candidatos a cargos eletivos. No primeiro caso, por meio de uma 
estratégia existente na FIERGS desde a década de 1990, de "interiorização da entidade", e que compreende, por exemplo, reuniões periódicas com representantes empresariais, mas, também, lideranças locais e regionais de diferentes regiões do Rio Grande do Sul. No segundo caso, por meio de reuniões de apresentação e de discussão de tais agendas especialmente com os candidatos ao executivo estadual, de modo geral em reuniões realizadas na própria sede da entidade, em Porto Alegre (CADONÁ, 2009).

A FIERGS, nessa direção, colocou-se como um centro irradiador de conscientização, mobilização, organização e lutas em defesa dos interesses de classe da burguesia industrial no Rio Grande do Sul. Como ensinava René Dreifuss, o exercício do poder de uma classe não se esgota com a história de confabulações e conchavos, de eleições e diretrizes de governo (DREIFUSS, 1986).

O poder de uma classe se expressa, também, no "preparo para a ação, pela potencialização dos atores" e, nesse processo, que não é espontâneo, certos "agentes coletivos" têm importância fundamental. São "agentes coletivos" que atuam como um "córtex político", ou seja, como órgãos que conseguem "visualizar objetivos estratégicos e táticos em cenários modificáveis", intervindo no interior das classes, buscando uma articulação hegemônica, procurando regular as relações divergentes, perseguindo a produção de uma coesão interna de classe. Mas, também, como "estado-maior", órgãos capazes de operacionalizar os objetivos de classe e de viabilizar a inserção política e ideológica da classe, pretendendo que os projetos particulares classistas se convertam em demandas gerais, "sociais", "nacionais" (DREIFUSS, 1986).

\section{"Plataforma de Compromissos para um Brasil Industrial": a agenda de desenvolvimento defendida pela FIERGS nas eleições de 2018}

Seguindo uma tradição consolidada a partir da década de 1990, em 2018 a diretoria da FIERGS elaborou um documento visando orientar os posicionamentos da entidade em relação às eleições de 2018. O documento, que recebeu o título "Plataforma de Compromissos para um Brasil Industrial", resultou de um estudo realizado pelo Grupo de Política Industrial, setor existente na FIERGS, com o objetivo de elaborar projetos de desenvolvimento industrial. $\mathrm{E}$ foi apresentado e discutido com os candidatos que concorreram ao executivo estadual em 2018, além de ter sido encaminhado aos postulantes à Presidência da República e à Confederação Nacional das Indústrias (FIERGS, 2019a). Após as eleições, o documento também foi discutido com deputados federais e estaduais eleitos pelo/no Rio Grande do Sul, e com o governador eleito, Eduardo Leite, do Partido da Social Democracia Brasileira (PSDB) (JORNAL DO COMÉRCIO, 14 de fevereiro de 2019). 
A novidade presente no contexto das eleições de 2018 é que a agenda de desenvolvimento articulada por meio da ação coletiva da burguesia industrial no Rio Grande do Sul (e liderada pela FIERGS) não pretendeu alcançar somente a discussão acerca do desenvolvimento do Rio Grande do Sul. A agenda de desenvolvimento defendida pretendeu discutir o próprio capitalismo no Brasil, num contexto de crise política e retorno de políticas governamentais mais claramente orientadas pelo ideário neoliberal (como ocorreu a partir do golpe de 2016, que destituiu Dilma Rousseff da Presidência da República e elevou à condição de Presidente Michel Temer.

Nos diferentes momentos de apresentação da "Plataforma", as lideranças da FIERGS destacaram o compromisso histórico da entidade com o encaminhamento de projetos de desenvolvimento (para o estado gaúcho e ao Brasil), a necessidade das autoridades governamentais estarem atentas às demandas da indústria, a importância de um projeto de desenvolvimento industrial para o país comprometido com a "modernização da economia" e a aproximação do setor brasileiro aos patamares de desenvolvimento alcançados pelos "países desenvolvidos".

Eu criei um grupo de empresários, com mais a unidade de estudos econômicos da casa, para estudar uma política industrial para o Brasil. Algo mais perene, não é esses planos de curto prazo, que vão e voltam e, via de regra, terminam se perdendo no caminho. Então é a nossa visão para desenvolver o país como um país industrial, pois os países desenvolvidos do mundo têm uma forte característica industrial (Gilberto Petry, Presidente da FIERGS. FIERGS, 2019b).

A Plataforma de Compromissos para um Brasil Industrial foi estruturada em cinco eixos, a partir dos quais a FIERGS destacou suas principais propostas para o desenvolvimento do capitalismo no Brasil: 1. Segurança Jurídica, desburocratização, simplificação e eficiência administrativa/tributária do setor público; 2. Infraestrutura e logística; 3. Adequação do tamanho e peso do setor público; 4. Inserção externa e novas tecnologias; 5. Empreendedorismo, indústria e sociedade (FIERGS, 2018). Logo na apresentação o documento indica seu caráter crítico em relação às políticas industriais implementadas pelos governos nacionais, em especial a partir dos anos 2000:

[...] por incrível que pareça, qualquer política industrial que o novo governo quiser aplicar no país, fatalmente não dará certo. Seria apenas uma tentativa fracassada como ocorre há mais de 20 anos em sucessivos planos de curta duração, editados e abandonados pelos seus resultados desprezíveis ou desastrosos. O caso mais recente foi a política dos supercampeões nacionais, de triste lembrança. 
Por que isto acontece? Simplesmente pelo fato de que o Brasil vive sufocado por uma série de questões estruturais. Os alicerces da economia nacional estão corroídos. Há um enorme custo de insegurança jurídica, extrema burocracia, anacronismo estrutural, privilégios descabidos a corporações de funcionários públicos, crônica escassez de investimentos, partidos interferindo em órgãos técnicos, serviços precários à sociedade...enfim, nada pode ser construído sobre essas bases movediças, pois tudo desaba ao menor vento (FIERGS, 2018, p. 2-3).

Em relação à Segurança Jurídica, desburocratização, simplificação e eficiência administrativa/tributária do setor público, o documento inicia fazendo uma avaliação crítica quanto à situação brasileira, em especial a partir do processo de democratização (excesso de leis, normas e regras, e alta carga tributária), e apresenta um conjunto de propostas visando encaminhar soluções para os problemas identificados, bem como para a definição das agendas governamentais no período entre 2019-2022: reforma tributária "visando simplificação e menor incidência de impostos sobre bens e serviços"; "ampliação do prazo de recolhimento de impostos federais"; previsibilidade e objetividade na "elaboração e aplicação das normas e leis"; "simplificação da compensação e ressarcimento dos tributos"; "reforma do PIS/Cofins sem aumento de carga tributária"; "revisão/limitação da Penhora on-line"; "facilitação das PPP's"; "promoção de uma postura orientativa e corretiva, e não punitiva, dos órgãos fiscalizadores"; "desburocratização dos procedimentos para licenciar empresas"; "desoneração tributária dos investimentos em todos os níveis"; "reforma tributária com alíquota interestadual única"; "reforma para simplificação do ICMS"; "ampliação do prazo de recolhimento do ICMS"; "modernização competitiva dos processos do Estado a fim de desburocratizar, simplificar e permitir a competição com os nossos pares internacionais" (FIERGS, 2018, p. 24-25).

Colocava-se, assim e nesse primeiro eixo, um conjunto de propostas que, desde os anos 1990, a burguesia industrial defendida, em especial em sua crítica ao Estado e à participação dele na regulamentação econômica e social. Note-se, inclusive, que durante os governos nacionais liderados pelo PT, uma crítica recorrente da burguesia industrial foi o "excesso de leis e de regulamentações", do que decorria uma insegurança jurídica aos investimentos do capital, em especial o capital estrangeiro (CADONÁ, 2016).

Em relação ao segundo eixo, Infraestrutura e logística, o documento critica a "infraestrutura deficiente", o "atraso logístico" e a "excessiva dependência do modal rodoviário". Propõe a seguinte agenda de ações: "privatizações e concessões"; "aprimoramento das agências reguladoras para fortalecer mercados e resguardar os consumidores, evitando a influência política"; "desenvolvimento e diversificação dos modais de transporte do país, com eliminação de reservas"; 
"política coerente de ocupação de solo, com o objetivo de evitar o conflito entre o urbano e a logística, bem como priorizar a eficiência de transporte"; "desenvolvimento da Cabotagem marítima costal com adequação do sistema portuário"; "privatização/fechamento EGR"; "melhorias no acesso ao Porto de Rio Grande, incluindo a conclusão da duplicação da BR-116 e criação de outros acessos ao porto"; "desenvolvimento e modernização do transporte hidroviário na Lagoa dos Patos"; e "desenvolvimento e modernização da malha ferroviária do RS” (FIERGS, 2018, p. 31-2).

Quanto ao terceiro eixo, Adequação do tamanho e peso do setor público, o documento destaca quatro pontos críticos, que "comprometem" a estabilidade macroeconômica e o planejamento do desenvolvimento econômico do país: dívida pública muito elevada, taxas de juros elevadas, spread bancário excessivo e regime previdenciário "insustentável". A partir desse diagnóstico, a agenda de ações propostas contempla: "reforma da Previdência"; "modernização do setor público para adequar os processos e carreiras a uma estrutura de Estado enxuta"; "independência do Banco Central"; "promoção da competitividade no setor bancário"; "reforma administrativa visando a diminuição de gastos"; "transparência dos custos e benefícios das empresas estatais para a sociedade e priorizando a venda do que não é função do Estado"; "restrição à estabilidade funcional e carreiras de Estado"; "cumprimento rigoroso da Lei de Responsabilidade Fiscal"; "reforma da Previdência estadual"; "estratégia para reposição de quadros de servidores que se tornam inativos"; "extinção da exigência de plebiscito para a venda das empresas estatais que não sejam função do Estado"; "cumprimento rigoroso da Lei de Responsabilidade Fiscal Estadual, e extensão de sua abrangência para o Legislativo e Judiciário"; "destinação orçamentária ao Legislativo, Judiciário, Ministério e Defensoria Pública de forma vinculada à receita efetivamente arrecadada pelo RS” (FIERGS, 2018, p. 39-40).

Nesse terceiro eixo, em especial, evidencia-se a tendência da burguesia industrial no Rio Grande do Sul em defender a agenda de desenvolvimento que se consolidou no país principalmente a partir do governo de Michel Temer (20162019), numa direção de redução dos gastos públicos, controle do déficit público, políticas de redução dos funcionários públicos e de "racionalização administrativa" dos serviços públicos, privatização das estatais, relativização dos compromissos democráticos na condução das políticas de "estabilidade econômica" e comprometimento das atividades estatais (destaque-se a proposta de "extinção da exigência de plebiscito para a venda de empresas estatais").

Em relação ao quarto eixo, Inserção externa e novas tecnologias, o documento destaca que o Brasil é "extremamente fechado" ao comércio internacional, possui "pequena inserção nas cadeias globais de produção" e tem "baixa capacidade de geração de conhecimento". E propõe, como agenda de ações: "realização de Acordos Comerciais com mercados relevantes"; "facilitação do acesso e redução de custo de insumos e tecnologias importadas sem similar nacional"; 
"simplificação dos procedimentos de acesso ao crédito para inovação"; "maior eficiência do INPI para registrar e proteger a inovação"; "abertura comercial vinculada ao aumento da escala de produção"; "plano de Estado para a gestão e planejamento da competitividade sistêmica do país"; "plano realista de fortalecimento dos clusters de produção já estabelecidos" (FIERGS, 2018, p. 46).

Por fim, em relação ao quinto eixo, Empreendedorismo, indústria e sociedade, o documento ressalta que "O mundo segue na direção da maior cooperação" entre trabalhadores e empregadores, destacando também que os "estados com o piso regional são os que menos crescem", que a "modernização trabalhista propicia novos empregos", que a "modernização trabalhista reduziu o litígio entre empregadores e empregados", que o Brasil "tem forte caráter empreendedor" e que há necessidade de "promover a cidadania", indicando que as "questões comportamentais" ("temperamento, falta de proatividade e relacionamento interpessoal inadequado") são as causas principais das demissões nas empresas (FIERGS, 2018, p. 54). E propõe, como agenda de ações: "preservação das conquistas da modernização trabalhista, que trouxe maior segurança jurídica ao setor empresarial"; "defesa do aprofundamento da reforma, perseguindo as melhores práticas dos países desenvolvidos"; "campanha publicitária "A importância da indústria"; "readequação das entidades públicas para favorecer empreendedorismo"; "aperfeiçoamento e defesa do "Sistema S"; "estímulo à cidadania, através de uma educação voltada para o empreendedorismo e para o desenvolvimento de novas tecnologias"; "extinção do Piso Regional" no Rio Grande do Sul (FIERGS, 2018, p. 55-56).

Como indicado anteriormente, desde a década de 1990, nos períodos eleitorais, a FIERGS elabora documentos visando apresentar, discutir e construir consensos em torno de suas "agendas de desenvolvimento". Como, por exemplo, em 1998 a entidade elaborou um documento com o título "A rearquitetura do Rio Grande do Sul - garantindo o futuro" (FIERGS, 1998), contendo 42 propostas, que estruturavam uma agenda de desenvolvimento definida a partir de cinco temas centrais: 1 - a competitividade da economia gaúcha num contexto de mundialização do capital; 2 - a reestruturação produtiva das empresas gaúchas; 3 o papel da esfera estadual do Estado na promoção do desenvolvimento; 4 - a inserção competitiva do Rio Grande do Sul no circuito de investimentos nacionais e internacionais; 5 - a questão social (FIERGS, 1998).

Num contexto de polarização política no Rio Grande do Sul, que sob o ponto de vista político-eleitoral teve como manifestação maior a disputa entre Antônio Brito, do PMDB (Partido do Movimento Democrático do Brasil) e Olívio Dutra, do PT, tanto nas eleições de 1994 quanto em 1998, a burguesia industrial tomou partido em favor do projeto defendido por Antônio Brito (CADONÁ, 2015).

Um projeto que partia de um "diagnóstico negativo" da economia gaúcha, dada as dificuldades de expansão na área industrial no contexto da "globalização da 
economia" (um perfil industrial fortemente identificado com "setores tradicionais" e "sem capital e tecnologias suficientes para enfrentar os desafios da concorrência internacional") (SCHMIDT, HERRLEIN JR., 2002, p. 272). E, em função de tal diagnóstico, propunha um desenvolvimento subnacional "exogenamente determinado" (SCHMIDT, HERRLEIN JR., 2002, p. 273), dependente de agentes externos, ainda que com uma participação ativa das políticas governamentais na criação de condições favoráveis de infraestrutura e de atração de capitais (SCHMIDT, HERRLEIN JR., 2002, p. 273).

Naquele contexto, portanto, a burguesia industrial no Rio Grande do Sul se posicionou favorável a um projeto de desenvolvimento subnacional identificado com o ideário neoliberal, a partir do qual se defendia uma reestruturação da atuação do Estado e de uma atuação mais favorável aos investimentos do capital. Por um lado, por meio da privatização de estatais, da concessão de serviços públicos para a iniciativa privada, da racionalização e da redução dos gastos públicos, da diminuição do quadro de funcionários públicos, da menor intervenção nas relações entre capital e trabalho. Por outro, por meio de uma subordinação das políticas governamentais aos interesses do capital, em especial as de subsídios / renúncias fiscais / criação de infraestrutura favorável, visando tornar os investimentos privados locais mais competitivos, mas, também, tornar o território gaúcho mais atrativo aos investimentos das empresas estrangeiras (naquele período, em especial as empresas vinculadas ao setor automobilístico).

Nas duas décadas que separam 1998 e 2018, o projeto neoliberal predominante no Brasil durante a década de 1990 entrou em crise e uma experiência (duradoura) de governos liderados pelo PT (2003 - 2016) implementou um programa "neodesenvolvimentista", que garantiu um período de maior crescimento econômico (comparado ao alcançado durante a década de 1990), conferiu maior importância ao mercado interno (ainda que não tenha rompido com a abertura econômica implementada durante a década de 1990), reativou as funções primário-exportadoras do capitalismo brasileiro, implementou políticas de distribuição de renda e de melhoria do poder de compara dos salários (BOITO JR., 2018, p. 106).

Num contexto de crise do programa neodesenvolvimentista, cujo curso terminou no impeachment de Dilma Rousseff, em 2016, a burguesia industrial no Rio Grande do Sul reafirmou seus compromissos com a agenda neoliberal já defendida durante a década de 1990. O documento produzido visando orientar as suas posições políticas no contexto das eleições de 2018, nesse sentido, é expressão dessa "profissão de fé" ao ideário neoliberal.

Por um lado, as críticas às ações estatais, presentes nos preâmbulos de cada um dos eixos da agenda defendida, são: insegurança jurídica, burocratização, alta carga tributária, ineficiência administrativa do setor público, excesso de fiscalização, infraestrutura deficiente, gastos elevados, regime previdenciário insustentável, 
protecionismo econômico que compromete a modernização econômica, intervenção indevida nas relações capital e trabalho, gastos expressivos com políticas de proteção social. Por outro lado, defendem maior liberdade econômica, menor compromisso com democratização do desenvolvimento econômico, reformas comprometidas com a desregulamentação, a privatização e a flexibilização das relações capital e trabalho.

São pressupostos presentes na agenda de ações propostas para os governantes (tanto executivo quanto legislativo): diminuição dos impostos, menor fiscalização pública das atividades privadas, racionalização das atividades estatais, privatização e concessões de estatais, menor interferência política nas ações do banco central, reforma da previdência (a partir do pressuposto de que a previdência representa gastos públicos que precisam ser racionalizados/reduzidos), redução dos gastos públicos, racionalização administrativa e diminuição dos gastos com funcionalismo público (estrutura estatal "enxuta"), dispensa de consultas à população quanto a políticas de privatização, extinção do piso regional, criação de uma cultura de empreendedorismo, maior adaptação das instituições públicas às necessidades do capital.

Entre a "crítica às atividades estatais" e a apologia das forças do mercado, há o interesse que o Estado aumente sua eficiência na construção de condições históricas favoráveis aos investimentos do capital: ações visando o "desenvolvimento e diversificação dos modais de transporte do país", melhoria no acesso aos portos, modernização do transporte hidroviários e ferroviários, plano estatal para gestão e planejamento da competitividade sistêmica do país, plano para fortalecimento dos clusters já estabelecidos, atuação forte do governo visando garantir e ampliar as reformas privatizantes (previdência e trabalhista, em especial).

Num contexto de crise econômica e política, tal como se configurou já a partir do início do segundo governo de Dilma Rousseff (2015 em diante), a burguesia industrial no Rio Grande do Sul reafirmou sua defesa a uma agenda neoliberal. Partindo, portanto, do pressuposto de que ela tem maior compromisso com os objetivos estruturais da acumulação do capital no país. Os principais pontos dessa agenda, são: aumentar a produtividade do capital e do trabalho, aprofundar a lógica de produção de mais-valia nas relações diretas entre capital e trabalho, aumentar a competitividade dos espaços locais/subnacionais no contexto da mundialização do capital, adaptar as ações estatais em favor de ganhos de competitividade do capital e em detrimento dos trabalhadores. $\mathrm{Na}$ defesa dessa agenda, como indicado, Estado e desenvolvimento não são excludentes, mas, antes, vale a máxima segundo a qual "o 'big market' não pode administrar sua própria crise sem a intervenção do Estado. Sua verdade é o oposto do que anuncia seu discurso teórico" (BRUNHOFF, 1991, p. 182). 


\section{Considerações finais}

A análise apresentada neste artigo pretendeu dar conta de aspectos da participação política da burguesia industrial no Rio Grande do Sul no contexto das eleições de 2018. Mais especificamente, a partir de um documento elaborado pela FIERGS visando orientar seus diálogos com candidatos ao legislativo e ao executivo (tanto em nível estadual quanto nacional), a análise enfatizou a agenda de desenvolvimento defendida pela burguesia industrial no Rio Grande do Sul naquele contexto político-eleitoral.

Por meio da apresentação dos eixos centrais da agenda de desenvolvimento colocada pela burguesia industrial, a análise pretendeu dar conta tanto da capacidade de atuação classista desse segmento regional da burguesia industrial no Brasil (a partir da atuação decisiva de sua principal entidade de representação de interesse), quanto dos pressupostos políticos e ideológicos que fundamentam seus posicionamentos, bem como da dinâmica de desenvolvimento do capitalismo no Brasil.

Se por um lado a análise indicou elementos importantes acerca da capacidade política das lideranças da FIERGS, no sentido de articular politicamente e criar coesão interna na burguesia industrial no Rio Grande do Sul, por outro também indicou que essas lideranças agem no sentido de criar consensos, junto aos governantes, em torno de seus interesses de classe (apresentados, sempre, como demandas gerais, representantes de interesses da "sociedade").

Ao mesmo tempo, sob o ponto de vista da agenda de desenvolvimento defendida pela burguesia, indicou-se que a mesma se sustenta num processo histórico de afirmação/reafirmação de pressupostos vinculados ao ideário neoliberal. Uma agenda que não exclui a atuação do Estado na construção de condições favoráveis ao desenvolvimento do capitalismo (no estado gaúcho e em nível nacional), mas pretende redefinir suas formas de atuação, numa perspectiva de distanciamento das demandas sociais e democratizantes vinculadas às classes populares e de trabalhadores e de aproximação com os interesses de acumulação do capital.

Como e o quanto essa agenda de desenvolvimento condiciona as relações políticas da burguesia industrial com as gestões dos governantes eleitos em 2018, inclusive com o governo do presidente eleito Jair Bolsonaro (PSL - Partido Social Liberal), é um dos desafios que o presente estudo permite que seja explorado por meio de novas investigações. 


\section{Referências}

BARBOSA, Agnaldo de S. interpretações sobre a burguesia industrial brasileira: um breve balanço. Estudos de Sociologia, Araraquara, 15, 31-44, 2003.

BOITO JR., Armando. Reforma e crise política no Brasil: os conflitos de classe nos governos do PT. Campinas: UNICAMP, 2018.

BRUNHOFF, Suzanne de. A hora do mercado: crítica do liberalismo. São Paulo: UNESP, 1991.

CADONÁ, Marco André. A burguesia industrial e o desenvolvimento subnacional no Rio Grande do Sul: uma análise a partir dos posicionamentos da FIERGS em relação ao salário mínimo estadual durante o governo de Yeda Crusius (2007 - 2010). Planejamento e Politicas Publicas, v. 46, p. 161-180, 2016.

CADONÁ, Marco André. Burguesia industrial e a Agenda de Desenvolvimento para o Rio Grande do Sul durante os anos 90. Desenvolvimento em Questão, v. 13, p. 295-321, 2015.

CADONÁ, Marco André. A inserção neoliberal: burguesia industrial e a inserção econômica do Rio Grande do Sul no processo de reestruturação do capitalismo no Brasil durante os anos 1990. Florianópolis: UFSC - Programa de Pós-Graduação em Sociologia Política. (Tese de Doutorado em Sociologia Política), 2009.

CARDOSO, Fernando Henrique. Empresário industrial e desenvolvimento econômico no Brasil. São Paulo: Difusão Europeia do Livro, 1964.

DINIZ, Eli; BOSCHI, Renato. Empresários, interesses e mercado: dilemas do desenvolvimento no Brasil. Belo Horizonte: UFMG, 2004.

DINIZ, Eli; BOSCHI, Renato. Empresário, estado e capitalismo no Brasil. Rio de Janeiro: Forense Universitária, 1978. 
DINIZ, Eli; BOSCHI, Renato; PEREIRA, Luiz Carlos Bresser. Depois do consenso neoliberal, o retorno dos empresários industriais? [online].

Disponível em:

http://www.bresserpereira.org.br/papers/2007/07.03.Empres\%C3\%A1 riosEliDi nizBresserPereira.9Outubro07.pdf [Acesso em: 25 jan. 2019].

DREIFUSS, René. A internacional capitalista: estratégias e táticas do empresariado transnacional (1918 - 1986). Rio de Janeiro: Espaço e Tempo, 1986.

FIERGS (FEDERAÇÃO DAS INDÚSTRIAS DO ESTADO DO RIO GRANDE DO SUL). FIERGS apresenta agenda de desenvolvimento para deputados. A Semana, 23 de janeiro de 2019.

FIERGS (FEDERAÇÃO DAS INDÚSTRIAS DO ESTADO DO RIO GRANDE DO SUL). A Plataforma de Compromissos da FIERGS. A Semana, 30 de janeiro de 2019.

FIERGS (FEDERAÇÃO DAS INDÚSTRIAS DO ESTADO DO RIO GRANDE DO SUL). Plataforma de Compromissos para um Brasil Industrial. Porto Alegre: FIERGS, 2018.

FIERGS (FEDERAÇÃO DAS INDÚSTRIAS DO ESTADO DO RIO GRANDE DO SUL). A rearquitetura do Rio Grande do Sul: garantindo o futuro. Porto Alegre: FIERGS, 1998.

GROS, Denise B. Empresariado e atuação política na Nova República: notas sobre as entidades liberais no Rio Grande do Sul. Indicadores Econômicos FEE. Porto Alegre, 17(4): 113-120, 1990.

GROS, Denise B. Burguesia industrial gaúcha e o estado nacional, 19641978. Dissertação (Mestrado em Sociologia) - Instituto de Filosofia e Ciências Humanas, Pontifícia Universidade Católica do Rio Grande do Sul, 1987.

JORNAL DO COMÉRCIO. FIERGS apresenta agenda da indústria para deputados. Jornal do Comércio, Porto Alegre, 14 fev. 2019. In: 
https://www.jornaldocomercio.com/_conteudo/politica/2019/02/670141FIERGS-apresenta-agenda-da-industria-a-deputados.html. Acesso em: 26 mar. 2019.

LAPIS, Naira Lima. A burguesia industrial gaúcha e sua relação com o capital estrangeiro: os anos 1964-73. Anais... XIII Encontro da ANPOCS GT: Elites Políticas. Caxambu, outubro 1989.

MANCUSO, Wagner P.; OLIVEIRA, Amâncio J. Abertura econômica, empresariado e política: os planos doméstico e internacional. Lua Nova, São Paulo, v. 69, p. 147-172, 2006.

SCHMIDT, Carlos; HERRLEIN Jr., Ronaldo. Notas sobre o desenvolvimento do Rio Grande do Sul: trajetória histórica e os projetos contemporâneos. Ensaios FEE, Porto Alegre, v. 23, n. 1, p. 255-284, 2002.

Endereço para correspondência:

Marco AndréCadoná - marco14cadona@hotmail.com Avenida Independência, 2293 - Universitário 96815-900 Santa Cruz do Sul/RS, Brasil 
Marco André Cadoná

106 | Revista Brasileira de Desenvolvimento Regional, Blumenau, 7 (3), P. 87-103, 2019 